\title{
Commentary
}

\section{Genomic advances and their impact on clinical trial design}

\author{
Sumithra J Mandrekar and Daniel J Sargent
}

Address: Department of Health Sciences Research, Mayo Clinic, Rochester, MN 55905, USA.

Correspondence: Sumithra J Mandrekar. Email: mandrekar.sumithra@mayo.edu

\begin{abstract}
Medical treatment for patients has historically been based on two primary elements: the expected outcome for the patient, and the ability of treatment to improve the expected outcome. The advance in genomic technologies has the potential to change this paradigm and add substantial value to current medical practice by providing an integrated approach to guide patient-specific treatment selection using the genetic make-up of the disease and the genotype of the patient. Specifically, genomic signatures can aid in patient stratification (risk assessment), treatment response identification (surrogate markers), and/or in differential diagnosis (identifying who is likely to respond to which drug(s)). Several critical issues, including scientific rationale, clinical trial design, marker assessment methods, cost and feasibility have to be carefully considered in the validation of biomarkers through clinical research before they can be routinely integrated into clinical practice. Here, we highlight the impact of genomic advances on various aspects of clinical trial design.
\end{abstract}

\section{Introduction}

Genomic signatures are being developed for various diseases to estimate disease-related patient trajectories (prognostic signatures) and to predict patient-specific outcome to different treatments (predictive tools) [1-14]. The ultimate clinical utility of a biomarker hinges on two fundamental questions: firstly, what is the added value of marker assessment in every patient in relation to the prevalence of the marker, specifically the incremental benefit of treatment selection based on the marker compared with the added costs and complexity induced by the measurement of such markers; and secondly, is the new treatment effective in all patients regardless of the marker status (the magnitude of benefit may differ within the marker-defined subgroups) or just in the markerdefined subgroup(s)? Critical components required for the validation of genomic biomarkers (either single markers or multi-marker signatures) include the choice of an appropriate clinical trial design, the choice of an adequate marker assessment method (immunohistochemistry, fluorescent in situ hybridization, real time PCR, highdimensional microarray- and proteomics-based classifiers, and so on), the reliability and reproducibility of the assay, the logistics and feasibility of obtaining biospecimens, and the costs involved with assessing marker status. Here, we highlight the impact of genomic advances on various aspects of trial design.

\section{Marker validation strategies}

Prognostic marker validation can be established using the marker and outcome data from a cohort of uniformly treated patients with adequate follow-up. The patients can be participants in a clinical trial, but a clinical trial is not necessarily required. Data from patients on the placebo arm or standard-of-care treatment arm of a trial (that is, the patients who are not given the drug being studied) can be used because a prognostic marker is associated with the disease or the patient and not with a specific therapy.

Designs for predictive marker validation are more complex and require, at a fundamental level, data from a randomized study. Such designs can be broadly classified into retrospective validation (using samples collected from a previously conducted randomized controlled trial (RCT)) and prospective validation (enrichment, all-comers, hybrid or adaptive analysis designs). Detailed discussions of these designs along with pertinent clinical examples have been published previously [15-23]. Data from an RCT and availability of specimens from a large number of patients are both essential for a sound retrospective validation, as otherwise it is impossible to isolate any causal effect of the marker on therapeutic efficacy from the multitude of other factors arising from a non-randomized design and/or selected samples [24,25]. An example of a well conducted, prospectively designed retrospective validation study that used previously collected samples is the colon cancer recurrence score based on a multi-gene real time PCR assay for predicting recurrence in stage II colon cancer [14].

\section{Using and incorporating genomic information in trial design}

The strength of the preliminary evidence has a major role in the design of a prospective marker validation trial. One key issue is the hypothesized effectiveness of the new treatment: is it effective in all patients regardless of the 
marker status or only within certain marker-defined subgroups? For example, in the case of trastuzumab, an enrichment design strategy was used on the basis of strong preliminary data in which only human epidermal growth factor receptor 2 (HER2)-positive breast cancer patients were eligible for two large randomized trials of trastuzumab in the adjuvant setting. These trials succeeded in identifying a subgroup of patients who received a significant benefit from trastuzumab combined with paclitaxel after doxorubicin and cyclophosphamide treatment [26]. However, subsequent analyses have raised the possibility of a beneficial effect of trastuzumab in a broader patient population than that defined in the two trials $[27,28]$. Therefore, unless there is compelling preliminary evidence that not all patients will benefit from the study treatment under consideration (such as there was for K-ras gene status in colorectal cancer [29,30]), it is prudent to include and collect specimens and follow-up from all patients (given that all patients are screened anyway) in the trial to allow future testing for other potential prognostic markers in this population, as well as for other marker assessment techniques. This paradigm of collecting specimens from all patients is currently being used in several large ongoing trials in lung cancer, colon cancer and breast cancer, where the primary aim is to validate a biomarker in either the entire population or only within a marker-defined subgroup [15,31-35].

Genomic advances not only continually influence the design of new trials, but also affect the (re)design of ongoing trials. Examples include (i) amending the design of ongoing clinical trials investigating panitumumab and cetuximab in colorectal cancer on the basis of the recent data that demonstrated that the benefit from these agents is restricted to patients with wild-type $K$-ras gene status [15], and (ii) informing the design of ongoing and planned trials for assessing the clinical efficacy of warfarin following the recently validated pharmacogeneticbased warfarin dosing algorithm [36]. Specifically, the ongoing US-based phase III trial testing cetuximab in addition to a combination of 5 -fluorouracil, leucovorin and oxaliplatin (FOLFOX) as adjuvant therapy in stage III colon cancer (trial number No147) has now been amended to accrue only patients with K-ras wild-type tumors. The primary analysis will be conducted by looking for associations that are significant at the 0.05 level in the $K$-ras wild-type patients. Following a closed testing procedure, if this analysis is statistically significant at $P=0.05$, the efficacy of the regimen in the entire population will also be tested at the 0.05 level, using the data from K-ras mutant tumors of approximately 800 patients who were previously enrolled on this trial before the amendment for including only the wild type $K$-ras patients.

\section{Biomarker assessment}

Whether a local laboratory (an on-site laboratory where the patient is treated) or a central laboratory (where all testing is done in one central facility determined at the start of the study) is required for testing of a biomarker in a prospective clinical trial depends on many factors, with the intended ultimate clinical use of the biomarker and the assay methodology being the two key components. One example is the post-hoc central testing for HER2 positivity in breast cancer, which showed a high degree of discordance with the local testing results [27,28]. This raises two important questions: (i) choice of using a central facility versus local laboratories for patient selection for therapeutic intervention trials, which in turn depends on the reliability and reproducibility of the assay and the complexity of the assay; and (ii) a potential need for a repeat assessment of the patient's marker status on a second sample, when feasible and ethically appropriate, if the first assessment deems the patient as having a 'normal' marker status and hence as ineligible for the trial in question.

\section{Conclusions}

In an era of individualized medicine, genomic signatures to capture the biological nature of the disease together with relevant patient-specific clinical and pathological information will be used to define the optimal therapeutic regimen for each patient. The clinical validation of biomarkers remains challenging given the multitude of marker assessment methods and the possibility that one drug can affect several molecular pathways. Two trials, I-SPY (investigation of serial studies to predict therapeutic response with imaging and molecular analysis) and BATTLE (biomarkerintegrated approaches of targeted therapy of lung cancer elimination trial), have attempted to address these issues by using diverse data types, in the case of I-SPY to identify biomarkers that predict the response to therapy, and in the case of BATTLE by randomizing patients to treatment choices on the basis of their multiple biomarker profiles [37-39].

The developmental pathway for genomic signatures and biomarker-directed therapies, from discovery to clinical practice, is complex. Two critical issues in the validation of genomic signatures are the choice of the clinical trial design according to the strength of the preliminary evidence, and questions surrounding the biomarker assays, such as the marker assessment methods, feasibility of obtaining the specimens, the reliability and reproducibility of the assay, and additional cost involved with assessing the marker status of every patient. Although genomic signatures theoretically provide an integrated approach to guide treatment selection and inform patient management, careful consideration of the issues outlined here are needed to determine the clinical utility of such biomarkers.

\section{Competing interests}

DJS has received honoraria and/or consulting fees from Genomic Health, Exiqon, Precision Therapeutics, Genentech and Amgen. 


\section{Authors' contributions}

SJM and DJS contributed to the conception, content and drafting of this commentary. Both authors have read and approved the final manuscript for publication.

\section{Acknowledgments}

The authors are supported in part by the National Cancer Institute Grants: Mayo Clinic Cancer Center (CA-15083) and the North Central Cancer Treatment Group (CA-25224).

\section{References}

1. Conley BA, Taube SE: Prognostic and predictive markers in cancer. Dis Markers 2004, 20:35-43.

2. Taube SE, Jacobson JW, Lively TG: Cancer diagnostics: decision criteria for marker utilization in the clinic. $A m \mathrm{~J}$ Pharmacogenomics 2005, 5:357-364.

3. Sequist LV, Bell DW, Lynch TJ, Haber DA: Molecular predictors of response to epidermal growth factor receptor antagonists in non-small-cell lung cancer. J Clin Oncol 2007, 25:587-595.

4. Bonomi PD, Buckingham L, Coon J: Selecting patients for treatment with epidermal growth factor tyrosine kinase inhibitors. Clin Cancer Res 2007, 13:s4606-s4612.

5. Slamon D: Herceptin: increasing survival in metastatic breast cancer. Eur J Oncol Nurs 2000, 4(Sa):24-29.

6. Paik S: Clinical trial methods to discover and validate predictive markers for treatment response in cancer. Biotechnol Annu Rev 2003, 9:259-267.

7. Augustine CK, Yoo JS, Potti A, Yoshimoto Y, Zipfel PA, Friedman HS, Nevins JR, Ali-Osman F, Tyler DS: Genomic and molecular profiling predicts response to temozolomide in melanoma. Clin Cancer Res 2009, 15:502-510.

8. Riedel RF, Porrello A, Pontzer E, Chenette EJ, Hsu DS, Balakumaran B, Potti A, Nevins J, Febbo PG: A genomic approach to identify molecular pathways associated with chemotherapy resistance. Mol Cancer Ther 2008, 7:31413149.

9. Garman KS, Acharya CR, Edelman E, Grade M, Gaedcke J, Sud S, Barry W, Diehl AM, Provenzale D, Ginsburg GS, Ghadimi BM, Ried T, Nevins JR, Mukherjee S, Hsu D, Potti A: A genomic approach to colon cancer risk stratification yields biologic insights into therapeutic opportunities. Proc Natl Acad Sci USA 2008, 105:19432-19437.

10. Anguiano A, Nevins JR, Potti A: Toward the individualization of lung cancer therapy. Cancer 2008, 113(Suppl 7):17601767.

11. Salter $\mathrm{KH}$, Acharya $\mathrm{CR}$, Walters $\mathrm{KS}$, Redman $\mathrm{R}$, Anguiano A, Garman KS, Anders CK, Mukherjee S, Dressman HK, Barry WT, Marcom KP, Olson J, Nevins JR, Potti A: An integrated approach to the prediction of chemotherapeutic response in patients with breast cancer. PLOS ONE 2008, 3:e1908.

12. Garman KS, Nevins JR, Potti A: Genomic strategies for personalized cancer therapy. Hum Mol Genet 2007, 16:R226R232.

13. Bonnefoi H, Potti A, Delorenzi M, Mauriac L, Campone M, Tubiana-Hulin M, Petit T, Rouanet P, Jassem J, Blot E, Becette V, Farmer P, André S, Acharya CR, Mukherjee S, Cameron D, Bergh J, Nevins JR, Iggo RD: Validation of gene signatures that predict the response of breast cancer to neoadjuvant chemotherapy: a substudy of the EORTC 10994/BIG 00-01 clinical trial. Lancet Oncol 2007, 8:1071-1078.

14. Kerr D, Gray R, Quirke P, Watson D, Yothers G, Lavery IC, Lee M, O'Connell MJ, Shak S, Wolmark N: A quantitative multigene RT-PCR assay for prediction of recurrence in stage II colon cancer: selection of the genes in four large studies and results of the independent, prospectively designed QUASAR validation study [abstract]. J Clin Oncol 2009, 27:4000.
15. Mandrekar SJ, Sargent DJ: Clinical trial designs for predic tive biomarker validation: theoretical considerations and practical challenges. J Clin Oncol, in press.

16. Mandrekar SJ, Sargent DJ: Clinical trial designs for predictive biomarker validation: one size does not fit all. $J$ Biopharm Stat 2009, 19:530-542.

17. Mandrekar SJ, Grothey A, Goetz MP, Sargent DJ: Clinical trial designs for prospective validation of biomarkers. Am J Pharmacogenomics 2005, 5:317-325.

18. Sargent DJ, Conley BA, Allegra C, Collette L: Clinical tria designs for predictive marker validation in cancer treatment trials. J Clin Oncol 2005, 23:2020-2027.

19. Hoering A, Leblanc M, Crowley JJ: Randomized phase III clinical trial designs for targeted agents. Clin Cancer Res 2008, 14:4358-4367.

20. Simon R, Maitournam A: Evaluating the efficiency of targeted designs for randomized clinical trials. Clin Cancer Res 2004, 10:6759-6763.

21. Maitournam A, Simon R: On the efficiency of targeted clinical trials. Stat Med 2005, 24:329-339.

22. Wang SJ, O'Neill RT, Hung HMJ: Approaches to evaluation of treatment effect in randomized clinical trials with genomic subset. Pharm Stat 2007, 6:227-244.

23. Jiang $\mathrm{W}$, Freidlin $\mathrm{B}$, Simon R: Biomarker-adaptive threshold design: a procedure for evaluating treatment with possible biomarker-defined subset effect. J Natl Cancer Inst 2007, 99:1036-1043.

24. Elsaleh H, Joseph D, Grieu F, Zeps N, Spry N, lacopetta B: Association of tumour site and sex with survival benefit from adjuvant chemotherapy in colorectal cancer. Lancet 2000, 355:1745-1750.

25. Elsaleh H, Powell B, McCaul K, Grieu F, Grant R, Joseph D, lacopetta B: p53 alteration and microsatellite instability have predictive value for survival benefit from chemotherapy in stage III colorectal carcinoma. Clin Cancer Res 2001, 7:1343-1349.

26. Romond EH, Perez EA, Bryant J, Suman VJ, Geyer Jr CE Davidson NE, Tan-Chiu E, Martino S, Paik S, Kaufman PA Swain SM, Pisansky TM, Fehrenbacher L, Kutteh LA, Vogel VG, Visscher DW, Yothers G, Jenkins RB, Brown AM, Dakhil SR, Mamounas EP, Lingle WL, Klein PM, Ingle JN, Wolmark N: Trastuzumab plus adjuvant chemotherapy for operable HER2-positive breast cancer. N Engl J Med 2005, 353:16731684.

27. Paik S, Kim C, Jeong J, Geyer CE, Romond EH, Mejia-Mejia O, Mamounas EP, Wickerham D, Costantino JP, Wolmark N: Benefit from adjuvant trastuzumab may not be confined to patients with IHC 3+ and/or FISH-positive tumors: Central testing results from NSABP B-31 [abstract]. J Clin Oncol 2007, 25:511.

28. Perez EA, Suman VJ, Davidson NE Martino S, Kaufman PA Lingle WL, Flynn PJ, Ingle JN, Visscher D, Jenkins RB: HER2 testing by local, central, and reference laboratories in specimens from the North Central Cancer Treatment Group N9831 intergroup adjuvant trial. J Clin Oncol 2006, 24:3032-3038.

29. Amado RG, Wolf M, Peeters M, Van Cutsem E, Siena S, Freeman DJ, Juan T, Sikorski R, Suggs S, Radinsky R, Patterson SD, Chang DD: Wild-type KRas is required for panitumumab efficacy in patients with metastatic colorectal cancer. J Clin Oncol 2008, 26:1626-1634

30. Karapetis CS, Khambata-Ford S, Jonker DJ, O'Callaghan CJ, Tu D, Tebbutt NC, Simes RJ, Chalchal H, Shapiro JD, Robitaille S, Price TJ, Shepherd L, Au HJ, Langer C, Moore MJ, Zalcberg JR: K-ras mutations and benefit from cetuximab in advanced colorectal cancer. N Engl J Med 2008, 359:17571765

31. Sparano JA, Paik S: Development of the 21-gene assay and its application in clinical practice and clinical trials. $J$ Clin Oncol 2008, 26:721-728.

32. Cardoso F, Van't Veer L, Rutgers E, Loi S, Mook S, PiccartGebhart MJ: Clinical application of the 70-gene profile: the MINDACT trial. J Clin Oncol 2008, 26:729-735. 
33. Bogaerts J, Cardoso F, Buyse M, Braga S, Loi S, Harrison JA, Bines J, Mook S, Decker N, Ravdin P, Therasse P, Rutgers E, van 't Veer LJ, Piccart M; TRANSBIG consortium: Gene signature evaluation as a prognostic tool: challenges in the design of the MINDACT trial. Nat Clin Pract Oncol 2006, 3:540-551.

34. Mook S, Van't Veer LJ, Rutgers EJ, Piccart-Gebhart MJ, Cardoso F: Individualization of therapy using MammaPrint: From development to the MINDACT trial. Cancer Genomics Proteomics 2007, 4:147-155.

35. Paik S, Shak S, Tang G, Kim C, Baker J, Cronin M, Baehner FL, Walker MG, Watson D, Park T, Hiller W, Fisher ER, Wickerham DL, Bryant J, Wolmark N: A multigene assay to predict recurrence of tamoxifen-treated, node-negative breast cancer. N Engl J Med 2004, 351:2817-2826.

36. International Warfarin Pharmacogenetics Consortium, Klein TE, Altman RB, Eriksson N, Gage BF, Kimmel SE, Lee MT, Limdi NA, Page D, Roden DM, Wagner MJ, Caldwell MD, Johnson JA: Estimation of the warfarin dose with clinical and pharmacogenetic data. $N$ Engl J Med 2009, 360:753764
37. Zhou X, Liu S, Kim ES, Herbst RS, Lee JJ: Bayesian adaptive design for targeted therapy development in lung cancer - a step towards personalized medicine. Clin Trials 2008, 5:181193.

38. Esserman J, Perou C, Cheang M, DeMichele A, Carey L, van 't Veer LJ, Gray J, Petricoin E, Conway K, Berry D: Breast cancer molecular profiles and tumor response of neoadjuvant doxorubicin and paclitaxel: the I-SPY TRIAL (CALGB 150007/150012, ACRIN 6657) [abstract]. J Clin Oncol 2009, 27:LBA515.

39. Lin C, Moore D, DeMichele A, Ollila D, Montgomery L, Liu M, Krontiras H, Gomez R, Esserman L: Detection of locally advanced breast cancer in the I-SPY TRIAL (CALGB 150007/150012, ACRIN 6657) in the interval between routine screening [abstract]. J Clin Oncol 2009, 27:1503.

Published: 13 July 2009

doi:10.1186/gm69

(c) 2009 BioMed Central Ltd 